\title{
Patterns of Meniscal Damage Associated with Acute ACL
}

\section{Rupture}

\author{
Keywords: Anterior cruciate ligament; Tear, Meniscus; Rupture; \\ Pattems

\begin{abstract}
Background / Aim: Meniscal injunies commonly occur in conjunction with ACL tears. This study was conducted to detemine the pattems of meniscus damage associated with ACL rupture and that is associated with ACL tear.
\end{abstract} \\ identify the commonest type of menisc us damage in our population
}

Methods: a retrospective chart review of patients with ACL rupture seen at the Orthopedics Department, King Khalid University Hospital, Riyadh, Saudi Arabia. Data collection included the presence or absence of meniscal tear, the type of meniscal tear diagnosed by $M R I$ or arthroscopy, the time of the initial $A C L$ injury and the time of meniscal tear, the duration between $A C L$ rupture and reconstruction surgery, age, gender and level of sports activity performed.ACL tears associated with meniscal tears were diagnosed by MRI.

Results: Of 294 patients, 175 (59.7\%) had medial meniscal tear, 91 (30.9\%) had lateral meniscal tear and 28 patients (9.5\%) with both medial and lateral tear. Mean age of patients was $27.98 \pm 6.8$ years. Patients who had medial tears were significantly older $(29.10 \pm 7.0$ years) compared to lateral ( $26.24 \pm 5.9$ years) and both ( $26.61 \pm 6.7$ years), $p=0.002$. There were no significant differences in the height, weight and BMI, level of sport and mode of injury in between the three groups.

Conclusion: Tears to the medial menisc us appeared to be the more common in ACL cases in our setting. The preponderance of the injury to the medial menisc us is associated to the olderage of the patients at presentation.

\section{Introduction}

Anterior cruciate ligament (ACL), as a primary stabilizing structure of knee is the most common disrupted ligament in acute trauma in the US every year [1,2]. On the other hand, the menisci play a crucial role in the dynamics of the knee. Their shape, attachment, and material properties contribute substantially to joint alignment and load transmission by distributing both tensile and compressive forces. Damage to the menisci can influence proprioception, stability, and mobility of the knee $[3,4]$. Risk factors for meniscal tears include prolonged or repeated deep knee bending, obesity, and sports [5]. Acute injury, as seen in alpine sports, involves complex dynamics, which can damage singular or multiple tissue structures of the knee $[5,6]$. Meniscal tears are typically thought to be initiated by coupled compression and twisting movements $[7,8]$ which can accompany high-energy maneuvers such as cutting, jumping, and landing during sporting events [9].

Meniscal injuries commonly occur in conjunction with ACL tears. A numerous studies have examined the occurrence of these injuries, with their presence being reported as $16 \%$ to $82 \%$ in knees with acute ligament tears and as high as $96 \%$ in knees with chronic ligament tears [10-14]. Magnetic resonance imaging (MRI) is valuable

\section{Journal of}

Orthopedics \& Rheumatology

\author{
Al Saran Y, Al Lhaidan A, Al Garni N, Al Aqee \\ $M$, Alomar A, Bin Nasser A, Fawzi Al jassir*, \\ Mohammed Zamzam
}

Orthopedic Research Chair, King Saud University, Riyadh, Saudi Arabia

*Address for Correspondence

Fawzi Fahad Al Jassir, Professor and Consultant Orthopedic Surgeon, Knee and Shoulder Reconstruction and Orthopedic Oncology, Department of Orthopedics (49), King Khalid University Hospital and College of Medicine, King Saud University, P.O. Box 7805, Riyadh 11472, Kingdom of Saudi Arabia, Tel: 966-1-4670871 Fax: 966-1-4679436; Email: aljassir@hotmail.com

Submission: 02 January 2014

Accepted: 20 February 2014

Published: 24 February 2014

Copyright: (C) 2014 Saran YA, et al. This is an open access article distributed under the Creative Commons Attribution License, which permits unrestricted use, distribution, and reproduction in any medium, provided the original work is properly cited.

Reviewed \& Approved by: Bashir A. Zikria, Assistant Professor, Johns Hopkins Department of Orthopaedics, Division of Sports Medicine, USA

tool, preferred than diagnostic arthroscopy in most patients with ligamentous and meniscal tears because it avoids the surgical risks of arthroscopy, with better accuracy in medial and lateral meniscus and ACL [15].

Lateral meniscal tears (LMTs) occur slightly more frequently than medial meniscal tears (MMTs) in knees with acute ACL injuries, $56 \%$ lateral versus $44 \%$ medial. [10,12]. MMTs however, are more common in chronic ACL deficiency $[10,12,14]$. This difference in tear occurrence is usually attributed to the anatomic and functional differences that exist between the two menisci, especially in the ACL deficient knee, the lateral meniscus relatively loosely attached to the tibial plateau which allows it to be quite mobile, whereas the medial meniscus, is firmly attached to the tibia, especially at the posterior horn $[12,16,17]$. This firm attachment allows the medial meniscus to act as a knee stabilizer, a significant restraint to anterior tibial translation in the ACL deficient knee [18-21]. The loss of ACL function increases tibial translation, allowing the meniscus to "engage" the femoral condyle and act as a wedge against the tibia [22,23], while others have suggested that mechanical trauma causes the MMTs in this setting $[12,18,20]$. Several studies have explored the relationship between ACL injury and meniscal tear [24-30]. Some showed preponderance of the LMTs in the acute setting and in osteoarthritis [24,25], others suggested the MMTs especially in acute reconstructions [26-29].

This study was conducted to determine the patterns of meniscus damage associated with ACL rupture and identify the commonest type of meniscus damage in our population that is associated with ACL tear.

\section{Methods}

Medical records of patients with ACL rupture covering a period 
Citation: Al Saran Y, Al Lhaidan A, Al Garni N, Al Aqeel M, Alomar A, et al. Patterns of Meniscal Damage Associated with Acute ACL Rupture. J Orthopedics Rheumatol. 2014;2(1): 4.

of 16 years (January 1996 to December 2012) seen at the author's institute were retrospectively reviewed. The collected data included the presence or absence of meniscal tear, the type of meniscal tear diagnosed by MRI or arthroscopy, the time of the initial ACL injury and the time of meniscal tear, the duration between ACL rupture and reconstruction surgery, age, gender, mode of injury and level of sports activity performed, height, weight.

BMI is calculated according to the Patient's height and weight, patient is considered obese if the BMI is above 30 according to the World Health Organization [31].

Sports level was classified as: professional athletes: (practicing a sport activity as a job, e.g. member of a team), recreational Athlete (considered a person, who is practicing a sport activity that is involving running and pivotal movements at least once in a week not professionally), non athlete (a person who is not practicing any kind of sport), patients with no clear statement regarding their level of sport are considered as missing data.

Mode of Injury is classified as direct (Injury was caused be a direct trauma to the patent, e.g. hit by another player, felt on his knees or road traffic accident) or non direct (Injury was caused without trauma, e.g. over rotating the knee while exercising).

Patients who were diagnosed with ACL rupture using MRI within 3 months of the injury, underwent primary arthroscopic ACL reconstruction at our institution and found to have meniscal damage diagnosed by MRI or arthroscopy were included in the study. Patients who had a chronic ACL tear or had undergone prior ipsilateral knee arthroscopy or surgery, those with osteoarthritis, with rheumatoid arthritis and patients who had undergone ACL rupture revision were excluded from the study. All images were obtained by routine knee MRI.

Types of Meniscal Tears were obtained from the reports of the MRI and Arthroscopy and were classified as (longitudinal, Degenerative, flap, radial, complex) as according to Tandogan et al. [32], De Smet [33].

Data collected were entered and coded systematically into a Microsoft Excel worksheet and were imported to a Predictive analysis software (PASW) program version 18 (SPSS, IBM, Chicago, Illinois, USA). Oneway analysis of variation (ANOVA) was used to compare means between the three groups (LMTs, MMTs and both). Pearson correlation was conducted to determine the relationship between the outcome variables (age, gender and sport levels). Independent sample $t$-test was done to identify differences between the mean values of continuous variables. Chi square test was done to determine associations between categorical variables. A test result considered statistically significant if $\mathrm{p}<0.05$.

\section{Results}

A total of 294 patients satisfied the inclusion criteria of the current study from 1996 to 2012. Of these patients, 175 (59.5\%) had MMTs, 91 (31\%) had LMTs and 28 patients (9.5\%) with both MMT and LMT (Table 1).

There were no significant differences in the height, weight, and BMI, level of sport and mode of injury in between the three groups
(MMTs, LMTs and both) (Table 2). Types of meniscal tears are shown in Table 3.

\section{Discussion}

In our study, the patients who had medial meniscal tearing were significantly older than those who had only lateral meniscal tear, and those who had both medial and lateral meniscal tears. No such relationship was significant between age and lateral meniscal tear. Our findings are in concordance with the findings of the

Table 1: Demographic characteristics of all patients with $A C L$ rupture with meniscus injury.

\begin{tabular}{|l|l|}
\hline Variables & \\
\hline Age in years, mean (SD) & $27.98(6.8)$ \\
\hline Weight in $\mathrm{kg}$, mean (SD) & $80.80(17.1)$ \\
\hline Height in cm, mean (SD) & $170.73(7.7)$ \\
\hline BMl in $\mathrm{kg} / \mathrm{cm}^{2}$, mean (SD) & $27.68(5.6)$ \\
\hline Mode of injury & \\
\hline Direct injury, $\mathrm{n}(\%)$ & $125(42.5)$ \\
\hline Non-direct injury, $\mathrm{n}(\%)$ & $169(57.4)$ \\
\hline Sports level & \\
\hline Professional athletes, $\mathrm{n}(\%)$ & $5(1.7)$ \\
\hline Recreational athletes, $\mathrm{n}(\%)$ & $196(66.7)$ \\
\hline Non-athlete, $\mathrm{n}(\%)$ & $28(9.5)$ \\
\hline No available data, $\mathrm{n}(\%)$ & $65(22.1)$ \\
\hline
\end{tabular}

Patients who had MMTs were significantly older ( $29.10 \pm 7.0$ years) compared to lateral ( $26.24 \pm 5.9$ years $)$ and both $(26.61 \pm 6.7$ years $), p=0.002$.

Table 2: Comparison between MMT, LMT and both in 294 patients who had ACL tear.

\begin{tabular}{|c|c|c|c|c|}
\hline Variables & $\begin{array}{c}\text { MMT } \\
n=175\end{array}$ & $\begin{array}{l}\text { LMT } \\
n=91\end{array}$ & $\begin{array}{l}\text { Both } \\
n=28\end{array}$ & $p$ values \\
\hline Age in years, mean (SD) & $29.10(7.0)$ & $26.24(5.9)$ & $26.61(6.7)$ & $0.002^{\wedge}$ \\
\hline Weight in kg. mean (SD) & $82.38(17.5)$ & $79.14(16.4)$ & $76.87(16.3)$ & $0.165^{\wedge}$ \\
\hline Height in $\mathrm{cm}$, mean (SD) & $170.40(8.1)$ & $171.42(6.6)$ & $170.49(8.1)$ & $0.602^{\wedge}$ \\
\hline BMI, mean (SD) & $28.34(5.6)$ & $26.83(5.6)$ & $26.43(5.2)$ & $0.062^{\wedge}$ \\
\hline Obesity, n (\%) & $56(32.0)$ & $22(24.2)$ & $7(25.0)$ & $0.294^{*}$ \\
\hline Type of ACL tear & & & & \\
\hline Direct ACL tear, n (\%) & 68 (38.9) & $32(35.2)$ & $9(32.1)$ & \multirow{2}{*}{$0.425^{\star}$} \\
\hline Indirect ACL tear, n (\%) & $65(37.1)$ & $30(33.0)$ & $8(28.6)$ & \\
\hline Level of sports & & & & \\
\hline Recreational athlete, n (\%) & $105(60.0)$ & $67(73.6)$ & $22(78.6)$ & \multirow{2}{*}{$0.144^{*}$} \\
\hline Professional athlete, $\mathrm{n}(\%)$ & $3(1.7)$ & $2(2.2)$ & $1(3.6)$ & \\
\hline
\end{tabular}

Note: ^ by ANOVA, * by Chi-square test

Table 3: Types of meniscal tears by MRI \& Arthroscopy.

\begin{tabular}{|l|l|l|l|}
\hline Types of Meniscal Tears & Medial & Lateral & Total \\
\hline Longitudinal Tears & $152(75 \%)$ & $86(72 \%)$ & $238(74 \%)$ \\
\hline Degenerative Tears & $16(8 \%)$ & $10(8 \%)$ & $26(8 \%)$ \\
\hline Radical Tears & $8(4 \%)$ & $9(7 \%)$ & $17(5 \%)$ \\
\hline Complex Tears & $6(3 \%)$ & $2(2 \%)$ & $8(2.5 \%)$ \\
\hline FLAP & $6(3 \%)$ & $5(4 \%)$ & $11(3.5 \%)$ \\
\hline N/A & $15(7 \%)$ & $7(7 \%)$ & $22(7 \%)$ \\
\hline Total & 203 & 119 & 322 \\
\hline
\end{tabular}


study that was conducted in Turkey by Tandogan et al. [32], which showed preponderant injury to the medial meniscus than the lateral meniscus, they also found that the mean age of the patients with medial meniscal tears was $27.0 \pm 7.6$ years, significantly older than those who had no medial meniscal tearing ( $25.4 \pm 6.7$ years). Our patient's mean age who had medial meniscal tearing was $29.10 \pm$ 7.0 years, significantly older than $26.61 \pm 6.7$ years in those who did not have medial meniscal tearing. Sports level was not significantly correlated to the parameters we have studied or to the site of meniscal tear. This is probably because most of our patients (66.8\%) were just recreational athletes.

Our study was in contrast to the findings of Bellabarba et al. [10] ,Thompson et al. [12], Melissa [34] wherein they found that LMTs are more frequently encountered than MMTs, and that MMTs on the other hand are more common in chronic injuries. Our study showed more frequent MMTs than LMTs, of patients with acute ACL injuries. Again, this is probably due to the older age of our patients, which was significantly correlated with MMTs.

Obesity, Mechanism of injury, Sport level as a risk factors of meniscal tear didn't show any significance in determining a common pattern, which goes with the same results that was found in Kluczynski et al. [34] where different risk factors have been examined prospectively to see their effect on meniscal tears and chondral changes.

The sensitivity of MRI in detecting meniscal pathology has been proven in several studies [10]. However, Oei in 2003 [35] pointed out the low sensitivity of MRI in detecting lateral meniscal pathology compared to detecting medial meniscal pathology with a sensitivity difference by as much as $14 \%$ (93.3\% versus $79.3 \%$ ), in an adult population, more so in the presence of ACL tears [36]. This window would probably explain the differences between the frequencies of LMTs and MMTs, more so in our findings, another point which could also explain our findings; is the common presentation of knee varus malalignment in Saudi population. In a comparison study between Saudi Arabian and Canadian cohorts by the same group, it was clearly found that in knee osteoarthritis patients Saudis had more varus alignment, showed by the Hip-Knee-Ankle angle parameter used to diagnose knee alignment disorders [37].

A study addressing the Knee alignment in the Saudi Population Comparing the means of Tibiofemoral angle (TFA) of different age groups in Saudi population to those of corresponding age groups in Japanese and Australian Caucasians showed a statistically significant lower TFA difference in all age groups. Comparison of the means of TFA of different age groups in Saudi population to those of corresponding age groups in Japanese and Australian Caucasians showed a statistically significant difference in all age groups, also Comparison of the means of TFA of Saudi males and females to those of Europeans, Chinese and American Caucasians showed a significant difference from all of them [38].

Genuvarus can result in added contact stresses on the medial compartment of the knee and possibly lead to accelerated wear and damage to the articular cartilage.

Another explanation for the significant association of older age to MMTs is the association of the medial meniscus posterior horn with severity of the chondral lesion and arthritic changes according to the $\mathrm{K}$-L radiographic score. There is usually accompanied chondral damage in MMTs [39].

Secondary medial meniscal tears are considered as the main reason of osteoarthritis followed by ACL deficiency [40]. The aim of this study is to alert the surgeons about the existence of this common finding in order to decrease future osteoarthritis. There were a few limitations in the study mainly because of its retrospective nature; a lot of the patient's X-rays were not found in order to study the alignment of the knees. In addition we were not able to obtain detailed information about the chondral lesions in the MRI reports to augment our significant findings of MMTs among our older-aged population.

\section{Conclusion}

The higher occurrence of medial meniscal tear in acute anterior cruciate tears could be attributed to the age related arthritic changes as well as to the common varus deformity in our population; this finding should be considered by the surgeons in order to decrease future osteoarthritis.

\section{References}

1. Griffin LY, Agel J, Albohm MJ, Arendt EA, Dick RW, et al. (2000) Noncontact anterior cruciate ligament injuries: Risk factors and prevention strategies. J Am Acad Orthop Surg 8: 141-150.

2. Grindstaff TL, Hammill RR, Tuzson AE, Hertel J (2006) Neuromuscular control training programs and noncontact anterior cruciate ligament injury rates in female athletes: A numbers-needed to treat analysis. J Athl Train 41: 450-456.

3. Aagaard H, Verdonk R (1999) Function of the normal meniscus and consequences of meniscal resection. Scand J Med Sci Sports 9: 134-140.

4. Jerosch J, Prymka M, Castro W (1996) Proprioception of knee joints with a lesion of the medial meniscus. Acta Orthop Belg 62: 41-45.

5. Baker P, Coggon D, Reading I, Barrett D, McLaren M, et al. (2002) Sports injury, occupational physical activity, joint laxity, and meniscal damage. J Rheumatol 29: 557-563.

6. RenstromP (1994) Clinical practice of sports injury prevention and care Olympic encyclopedia of sports medicine. Oxford, London, Edinburgh Boston, Melbourne, Berlin, Paris, Vienna: Blackwell Scientific Publications, LTD.

7. Muellner T, Nikolic A, Vecsei V (1999) Recommendations for the diagnosis of traumatic meniscal injuries in athletes. Sports Med 27: 337-345.

8. Slocum DB, Larson RL (1968) Rotatory instability of the knee: Its pathogenesis and a clinical test to demonstrate its presence. J Bone Joint Surg Am 50: 211225.

9. Muellner T, Weinstabl R, Schabus R, Vécsei V, Kainberger F, et al. (1997) The diagnosis of meniscal tears in athletes: A comparison of clinical and magnetic resonance imaging investigations. Am J Sports Med 25: 7-12.

10. Bellabarba C, Bush-Joseph CA, Bach BR Jr (1997) Patterns of meniscal injury in the anterior cruciate-deficient knee: A review of the literature. Am J Orthop 26: 18-23.

11. Yoon KH, Yoo JH, Kim KI (2011) Bone contusion and associated meniscal and medial collateral ligament injury in patients with anterior cruciate ligament rupture. J Bone Joint Surg Am 93: 1510-1518.

12. Thompson WO, Fu FH (1993) The meniscus in the cruciate-deficient knee. Clin Sports Med 12: 771-796.

13. Panisset JC, Duraffour $\mathrm{H}$, Vasconcelos W, Colombet $\mathrm{P}$, Javois $\mathrm{C}$, et al. (2008) Clinical, radiological and arthroscopic analysis of the ACL tear. A prospective study of 418 cases. Rev Chir Orthop Reparatrice Appar Mot 94: 362-368. 
Citation: Al Saran Y, Al Lhaidan A, Al Garni N, Al Aqeel M, Alomar A, et al. Patterns of Meniscal Damage Associated with Acute ACL Rupture. J Orthopedics Rheumatol. 2014;2(1): 4.

14. Wickiewicz TL (1990) Meniscal injuries in the cruciate-deficient knee. Clin Sports Med 9: 681-694.

15. Crawford R, Walley G, Bridgman S, Maffulli N (2007) Magnetic resonance imaging versus arthroscopy in the diagnosis of knee pathology concentrating on meniscal lesions and ACL tears: a systematic review. Br Med Bull 84 5-23.

16. Villegas DF, Hansen TA, Liu DF, Donahue TL (2008) A quantitative study of the microstructure and biochemistry of the medial meniscal horn attachments. Ann Biomed Eng 36: 123-131.

17. Kan A, Oshida M, Oshida S, Imada M, Nakagawa T, et al. (2010) Anatomical significance of a posterior horn of medial meniscus: The relationship between its radial tear and cartilage degradation of joint surface. Sports Med Arthrosc Rehabil Ther Technol 2:1.

18. Allen CR, Wong EK, Livesay GA, Sakane M, Fu FH, et al. (2000) Importance of the medial meniscus in the anterior cruciate ligament-deficient knee. J Orthop Res 18: 109-115.

19. Hsieh $\mathrm{H}-\mathrm{H}$, Walker PS (1976) Stabilizing mechanisms of the loaded and unloaded knee joint. J Bone Joint Surg Am 58: 87-93.

20. Indelicato PA, Bittar ES (1985) A perspective of lesions associated with ACL insufficiency of the knee: A review of 100 cases. Clin Orthop Relat Res 198: 77-80

21. Markolf KL, Kochan A, Amstutz HC (1984) Measurement of knee stiffness and laxity in patients with documented absence of the anterior cruciate ligament. J Bone Joint Surg Am 66: 242-252.

22. Levy IM, Torzilli PA, Warren RF (1982) The effect of medial meniscectomy on anterior-posterior motion of the knee. J Bone Joint Surg Am 64: 883-888.

23. Sullivan D, Levy IM, Sheskier S, Torzilli PA, Warren RF, et al. (1984) Media restraints to anteriorposterior motion of the knee. J Bone Joint Surg Am 66: 930-936

24. Cipolla M, Scala A, Gianni E, Puddu G (1995) Different patterns of menisca tears in acute anterior cruciate ligament $(A C L)$ ruptures and in chronic $A C L-$ deficient knees. Classification, staging and timing of treatment. Knee Surg Sports Traumatol Arthrosc 3: 130-134

25. Nikolic DK (1998) Lateral meniscal tears and their evolution in acute injuries of the anterior cruciate ligament of the knee. Arthroscopic analysis. Knee Surg Sports Traumatol Arthrosc 6: 26-30.

26. Cerabona F, Sherman MF, Bonamo JR, Sklar J (1988) Patterns of menisca injury with acute anterior cruciate ligament tears. Am J Sports Med 16:603609

27. Keene GC, Bickerstaff D, Rae PJ, Paterson RS (1993) The natural history of meniscal tears in anterior cruciate insufficiency. Am J Sports Med 21:672679

28. Paletta GA, Levine DS, O'Brien SJ, Wickiewicz TL, Warren RF (1992) Patterns of meniscal injury associated with acute anterior cruciate ligament injury in skiers. Am J Sports Med 20: 542-547.

29. Smith JP III, Barrett GR (2001) Medial and lateral meniscal tear patterns in anterior cruciate ligament deficient knees. Am J Sports Med 29: 415-419.

30. Kaeding CC, Pedroza AD, Parker RD, Spindler KP, McCarty EC, et al. (2005) Intra-articular findings in the reconstructed multiligament injured knee. Arthroscopy 21: 424-430.

31. WHO (2000) Obesity: Preventing and Managing the Global Epidemic. Report of a WHO consultation. World Health Organ Tech Rep Ser.

32. Tandogan RN, Taşer O, Kayaalp A, Taşkiran E, Pinar H, et al. (2004) Analysis of meniscal and chondral lesions accompanying anterior cruciate ligament tears: relationship with age, time form injury, and level of sport. Knee Surg Sports Traumatol Arthrosc 12: 262-270.

33. De Smet AA (2012) How I diagnose meniscal tears on knee MRI. AJR Am J Roentgenol 199: 481-499.

34. Kluczynski MA, Marzo JM, Bisson LJ (2013) Factors Associated With Meniscal Tears and Chondral Lesions in Patients Undergoing Anterio Cruciate Ligament Reconstruction: A Prospective Study Am J Sports Med 41: $2759-2765$

35. Oei EH, Nikken JJ, Verstijnen AC, Ginai AZ, Myriam Hunink MG (2003) MR imaging of the menisci and cruciate ligaments: a systematic review. Radiology 226: 837-848.

36. De Smet AA, Mukherjee R (2008) Clinical, MRI, and arthroscopic findings associated with failure to diagnose a lateral meniscal tear on knee MRI. AJR Am J Roentgenol 190: 22-26.

37. Cooke TD, Harrison L, Khan B, Scudamore A, Chaudhary MA (2002) Analysis of limb alignment in the pathogenesis of osteoarthritis: a comparison of Saudi Arabian and Canadian cases. Rheumatol Int 22: 160-164.

38. El Fouhil AF, Khoshhal KI, Al-Nakshabandi NA, Al-Boukai AA, Atteya M (2011) Normal knee angles in the adult Saudi population. Saudi Med J 32: 1143-1148.

39. Ozkoc G, Circi E, Gonc U, Irgit K, Pourbagher A, et al. (2008) Radial tears in the root of the posterior horn of the medial meniscus. Knee Surg Sports Traumatol Arthrosc 16: 849-854.

40. Lohmander LS, Englund PM, Dahl LL, Roos EM (2007) The longterm consequence of anterior cruciate ligament and meniscus injuries: Osteoarthritis. Am J Sports Med 35: 1756-1769. 